\title{
RESTAURAÇÂO USANDO A TÉCNICA DA MURALHA DE SILICONA
}

Letícia Tiyono TOMOKUNI, Andreia ASCOLI, Anni Keroly MONTEIRO, Cintia Gaio MURAD

Um sorriso esteticamente agradável é um dos grandes desafios aos cirurgiõesdentistas. Para a reconstrução de dentes anteriores com fraturas ou restaurações envolvendo ângulo incisal, a dentística restauradora utiliza a técnica de restauração usando a muralha de silicona, que oferece a cópia ideal da estrutura palatina. Esta técnica tem se consolidado entre os profissionais da área, pois permite recuperar a estética de forma rápida, conservadora e com custos reduzidos para o paciente. Neste trabalho, será descrito um caso clínico de um paciente gênero feminino, raça branca, 13 anos de idade, que foi encaminhada à Clínica de Odontologia do Centro Universitário de Maringá, apresentando uma fratura oblíqua da coroa do dente 11. Como solução para este caso, foi proposta a restauração com resina composta, empregando-se essa técnica. Após receber os procedimentos emergenciais, a paciente teve suas arcadas moldadas em hidrocolóide irreversível, e posterior confecção de modelo de gesso. Em seguida, o dente fraturado foi reconstruído com cera e confeccionado a muralha. Na sessão seguinte, foi realizada a restauração, devolvendo a anatomia natural como mamelões e área translúcida da incisal e a reabilitação funcional do dente, proporcionando ao paciente melhor estética e auto-estima. 